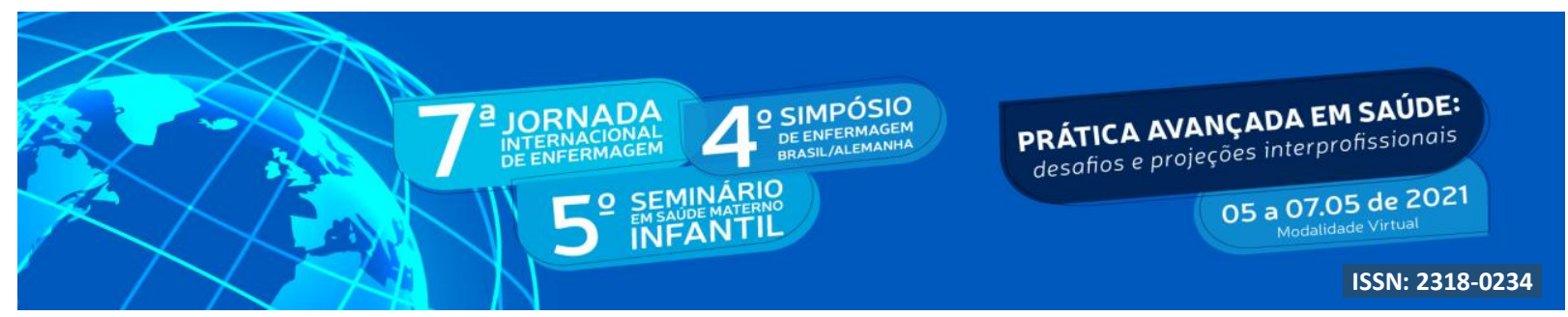

DOI: http://doi.org/10.48195/jie2021-127

\title{
EDUCAÇÃO ALIMENTAR E NUTRICIONAL NA ESCOLA POR MEIO DE JOGOS
}

\section{Marcia Montagner'1; Ana Paula Gularte Barbosa ${ }^{2}$; Michele Vargas Reginatto ${ }^{3}$; Nicholas Doviggi Meyer $^{4}$; Sarita Müller5; Franceliane Jobim Benedetti6}

\section{RESUMO}

O objetivo da presente pesquisa é identificar na literatura ações de Educação Alimentar e Nutricional (EAN) na escola por meio de jogos. Foi realizada uma revisão narrativa da literatura, nos meses de junho a setembro de 2020, em periódicos da área da saúde. Percebeu-se que as pesquisas incluíram indivíduos de ambos os gêneros, com grande variação etária, juntas somaram 4.055 indivíduos envolvidos e todas tinham como objetivo a alimentação saudável. Dentre os jogos, houve predomínio de jogo de cartas, seguido por videogames e por último, jogo de tabuleiro. Verificou-se, através desta pesquisa, que o uso de jogos como ferramenta de EAN, ainda, é ínfimo, apesar deles serem um fenômeno universal.

Palavras-chave: Alimentação Saudável; Escola; Educação Alimentar e Nutricional; Jogos.

\begin{abstract}
The objective of this research is to identify in the literature actions of Food and Nutrition Education (EFN) in schools through games. A narrative review of the literature was carried out, from June to September 2020, in health area journals. It was noticed that the researches included individuals of both genders, with great age variation, in which together they totaled 4,055 individuals involved and all aimed at healthy eating. Among the games, there was a predominance of card games, followed by video games and lastly, board games. It was observed, through this research, that the use of games as an EFN tool is still very insignificant, despite the fact that they are a worldwide phenomenon.
\end{abstract}

Keywords: Healthy Eating; School; Food and Nutrition Education; Games.

\section{INTRODUÇÃO}

A Educação Alimentar e Nutricional - EAN é o campo do conhecimento e de prática contínua e permanente, transdisciplinar, intersetorial e multiprofissional que visa promover a prática autônoma e voluntária de hábitos alimentares saudáveis, para poder assegurar o

\footnotetext{
${ }^{1}$ Ma. em Saúde Materno Infantil.Universidade Franciscana- UFN. E-mail: mtmontagner@gmail.com

${ }^{2}$ Ma. em Saúde Materno Infantil.Universidade Franciscana- UFN. E-mail: anapaulab6@gmail.com

${ }^{3}$ Ma. em Saúde Materno Infantil.Universidade Franciscana- UFN. E-mail: mi.reginatto@gmail.com

${ }^{4}$ Aluno dos cursos de Nutrição e Jogos Digitais- UFN. E-mail: nicholas.doviggi@ufn.edu.br

${ }^{5}$ Bela. em Nutrição- UFN. Nutricionista em do Arroio do Tigre- RS. E-mail: saritamullernutri@gmail.com

6 Profa. Dra. nos Cursos de Nutrição e Mestrado Profissional em Saúde Materno Infantil.- UFN. Email:franceliane@ufn.edu.br 


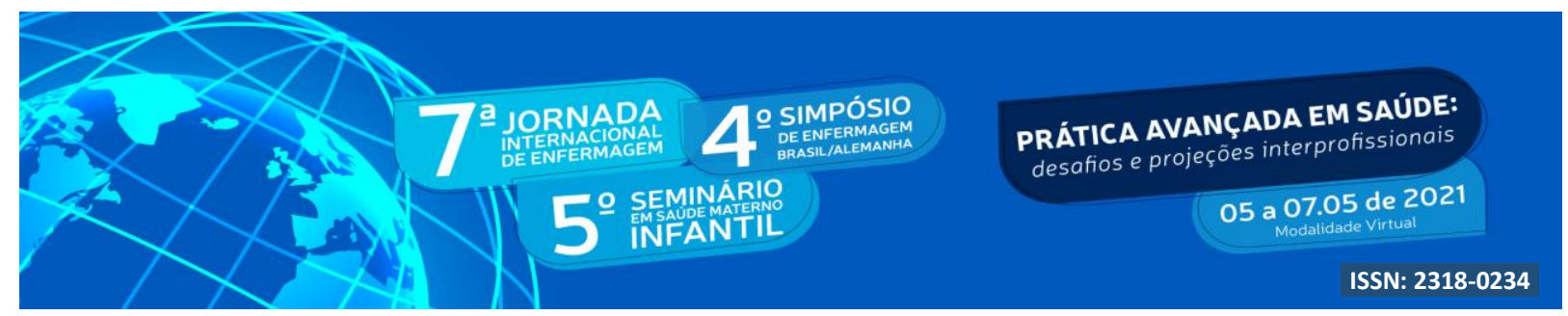

Direito Humano à Alimentação Adequada (DHAA) (BRASIL, 2018).

Pelo Decreto No 7.272 (BRASIL, 2010), a EAN é uma diretriz da Política Nacional de Segurança Alimentar e Nutricional (PNSAN) e se constitui uma estratégia preconizada pelas políticas públicas em alimentação e nutrição (RAMOS; SANTOS; REIS, 2013). E, a partir da criação do Marco de Referência de EAN (BRASIL, 2012), encontram-se várias iniciativas para o fomento e fortalecimento da EAN nas redes de assistência social, saúde e educação e em outros cenários.

A importância de uma boa alimentação tem sido bastante discutida em diversas espaços, destacando-se a escola, ambiente propício para a aplicação de programas de educação em saúde e, para isso, a adoção de programas de educação nutricional vem sendo criado em diversos países e eles beneficiam alunos (as) nos diferentes ciclos da vida, pois com orientações sobre alimentação saudável, podem fazer escolhas conscientes, que trarão melhor qualidade de vida (DAVANÇO; TADDEI; GAGLIANONE, 2004).

Nesse sentido, atividades lúdicas como os jogos podem ser uma boa ferramenta para auxiliar nas ações de EAN na escola. Em Kishimoto (2008), a utilização da ludicidade potencializa a construção do conhecimento, já que permite às crianças identificar, classificar, agrupar, ordenar, simbolizar e combinar informações, ao mesmo tempo em que desenvolvem a atenção e a concentração.

Definir jogo não é tarefa fácil, pois o conceito varia conforme o contexto em que está inserido (KISHIMOTO, 2011). Jogo é uma atividade livre, conscientemente, tomada como "não-séria" e exterior à vida habitual, mas ao mesmo tempo capaz de absorver o jogador de maneira intensa e total, praticada dentro de limites espaciais e temporais próprios, segundo uma certa ordem e regras livremente consentidas, mas obrigatórias dotado de um fim em si mesmo e, ainda, promove a formação de grupos sociais (HUIZINGA, 2000).

\section{OBJETIVO}

Identificar na literatura ações de EAN na escola por meio de jogos. 


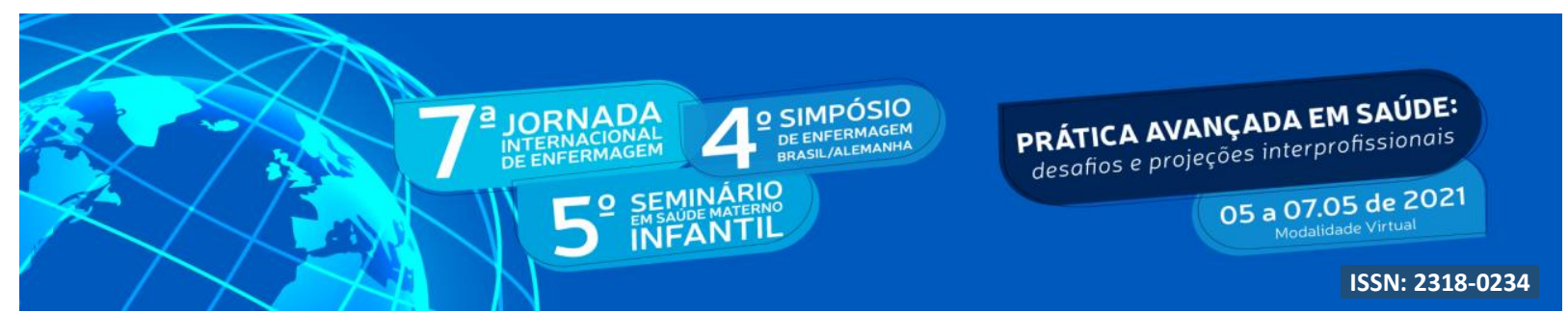

\section{METODOLOGIA}

Realizou-se uma revisão narrativa da literatura, nos meses de junho a setembro de 2020, em bases de dados e bibliotecas digitais da área da saúde: National Library of Medicine (PubMed), Science Direct, Scientific Electronic Library Online (SciELO) e Literatura LatinoAmericana em Ciências da Saúde (Lilacs), com o propósito de identificar pesquisas que utilizam jogos para auxiliar as ações de EAN realizadas no espaço escolar.

Utilizou-se os seguintes descritores em português, inglês e espanhol: "Alimentação" (Food, Pienso), "Jogo" (Game, Juego) "Educação Alimentar e Nutricional" (Food and Nutrition Education, Educación Alimentaria y Nutricional) e o operador booleano "AND”. A seleção seguiu os seguintes critérios de inclusão: últimos 10 anos de publicação; texto completo para o acesso; idiomas em português, inglês e espanhol; que apresentassem como foco do estudo a EAN e/ ou jogo e, foram excluídas monografias, dissertações, teses, revisões e apresentações em eventos.

\section{RESULTADOS E DISCUSSÃO}

Os artigos, que utilizam jogos para auxiliar as ações de EAN no espaço escolar, foram selecionadas e seus dados foram sistematizados (Quadro 1), com informações com seguintes critérios: dados da publicação (autor, título, país, periódico e ano), objetivos, métodos (delineamento, população, instrumento), resultados e conclusões. 


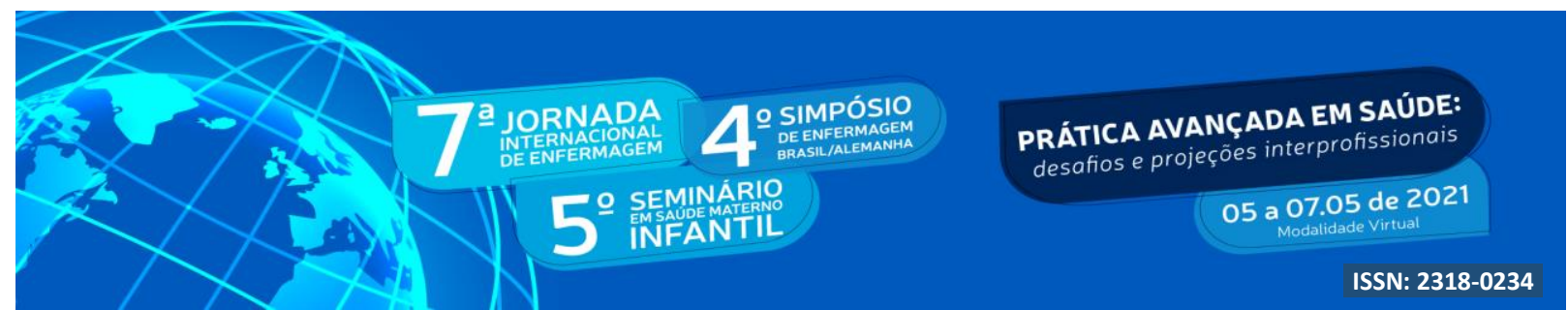

Quadro 1. Descrição das pesquisas que utilizam jogos como ferramenta para EAN na escola.

\begin{tabular}{|c|c|c|c|c|}
\hline $\begin{array}{c}\text { Autor(es)/Título } \\
\text { /Ano/País } \\
\text { Periódico }\end{array}$ & Objetivo & Metodologia & Resultado & Conclusão \\
\hline $\begin{array}{l}\text { LAKSHMAN et al. } \\
\text { A novel school- } \\
\text { based intervention } \\
\text { to improve } \\
\text { nutrition in } \\
\text { knowledge cluster } \\
\text { children: } \\
\text { randomised } \\
\text { controlled trial. } \\
\text { 2010/ Reino Unido } \\
\text { BMC Public Healt. }\end{array}$ & $\begin{array}{l}\text { Avaliar a eficácia e } \\
\text { a aceitabilidade de } \\
\text { uma intervenção } \\
\text { para aumentar o } \\
\text { conhecimento } \\
\text { sobre nutrição e } \\
\text { escolhas } \\
\text { alimentares mais } \\
\text { saudáveis entre } \\
\text { crianças de escolas } \\
\text { primárias. }\end{array}$ & $\begin{array}{l}\text { nsaio clínico } \\
\text { controlado } \\
\text { randomizado } \\
38 \quad \text { escolas } \\
\text { primárias estaduais } \\
\text { n=2519 crianças } 9 \\
\text { - } 11 \text { anos } \\
\text { Jogo de cartas Top } \\
\text { Grub. }\end{array}$ & $\begin{array}{l}12 \text { intervenções e } \\
13 \text { escolas de } \\
\text { controle }(n=1133) \text {. } \\
\text { O conhecimento } \\
\text { nutricional } \\
\text { aumentou tanto na } \\
\text { intervenção quanto } \\
\text { no controle. }\end{array}$ & $\begin{array}{l}\text { O jogo facilitou a } \\
\text { educação nutricional. } \\
\text { Novos estudos devem } \\
\text { determinar se melhorias } \\
\text { no conhecimento } \\
\text { nutricional } \\
\text { sustentadas e levar a } \\
\text { mudanças } \\
\text { comportamento } \\
\text { alimentar. }\end{array}$ \\
\hline $\begin{array}{l}\text { PEREZ LOPEZ; } \\
\text { DELGADO } \\
\text { FERNANDEZ. } \\
\text { Un juego de cartas } \\
\text { durante los recreos } \\
\text { escolares mejora } \\
\text { los hábitos } \\
\text { alimentarios en } \\
\text { adolescentes. } \\
\text { 2012/ Espanha } \\
\text { Nutr. Hosp. }\end{array}$ & $\begin{array}{l}\text { Melhorar os } \\
\text { hábitos alimentares } \\
\text { em adolescentes } \\
\text { por meio de jogo } \\
\text { de cartas }\end{array}$ & 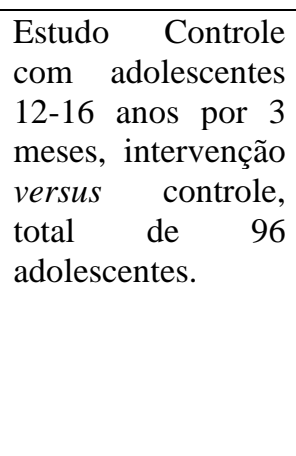 & $\begin{array}{l}\text { Após a intervenção, } \\
\text { melhorias } \\
\text { significativas em } 5 \\
\text { dos } 6 \text { hábitos } \\
\text { abordados no grupo } \\
\text { intervenção e no } \\
\text { grupo controle não } \\
\text { houve diferenças } \\
\text { significativas em } \\
\text { nenhum deles. }\end{array}$ & $\begin{array}{l}\text { A intervenção com o } \\
\text { jogo melhorou os hábitos } \\
\text { alimentares, mas não } \\
\text { houve } \\
\text { significativas no grupo } \\
\text { controle. }\end{array}$ \\
\hline $\begin{array}{l}\text { PIZIAK, } \\
\text { A pilot study of a } \\
\text { pictorial bilingual } \\
\text { nutrition education } \\
\text { game to improve } \\
\text { the consumption of } \\
\text { healthful foods in a } \\
\text { head start } \\
\text { population. } \\
\text { 2012/ EUA } \\
\text { Res Public Health } \\
\text { Int J Environ Res } \\
\text { Public Health }\end{array}$ & $\begin{array}{l}\text { Avaliar um jogo de } \\
\text { educação } \\
\text { nutricional } \\
\text { bilíngue. }\end{array}$ & $\begin{array}{l}\text { Estudo piloto } \\
413 \text { crianças } \\
(3-5 \text { anos) e seus } \\
\text { pais no Head Start } \\
\text { do Condado de } \\
\text { Bastrop- Texas } \\
\text { Jogo Tabuleiro. }\end{array}$ & $\begin{array}{l}\text { Aumentou } \\
\text { consumo de } \\
\text { vegetais na escola e } \\
\text { em casa, promoveu } \\
\text { o reconhecimento } \\
\text { de rários } \\
\text { alimentos, } \\
\text { aumentou consumo } \\
\text { de água e diminuiu } \\
\text { o de bebidas } \\
\text { açucaradas } \\
\text { alimentos com alto } \\
\text { teor de açúcar. }\end{array}$ & $\begin{array}{l}\text { A pesquisa mostrou que } \\
\text { o uso do jogo, além de } \\
\text { incorporar elementos do } \\
\text { mexicano-americano e } \\
\text { ser barato, pode melhorar } \\
\text { o consumo de vegetais } \\
\text { na faixa etária. }\end{array}$ \\
\hline
\end{tabular}




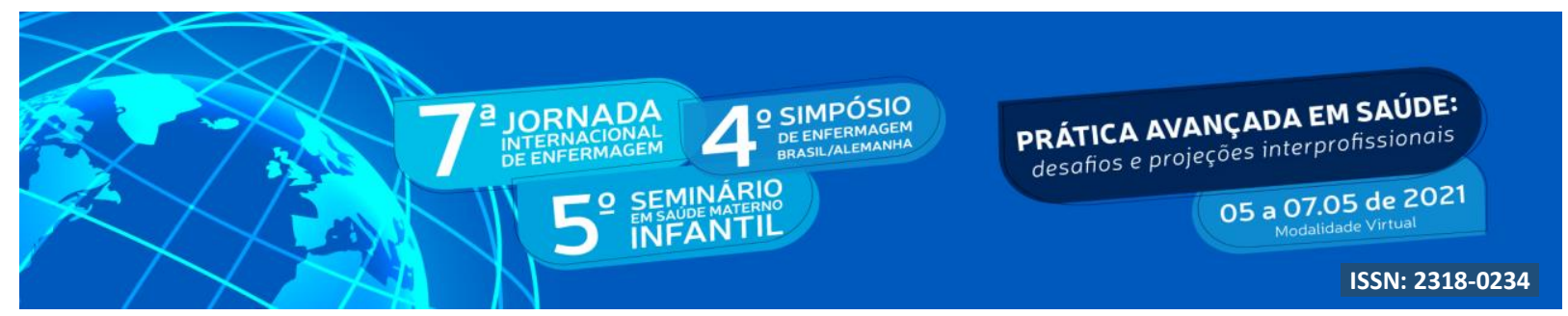

\begin{tabular}{|c|c|c|c|c|}
\hline $\begin{array}{l}\text { HERMANS et al. } \\
\text { Feed the Alien! The } \\
\text { Effects of a } \\
\text { Nutrition } \\
\text { Instruction } \\
\text { Game } \\
\text { Children's } \\
\text { Nutritional } \\
\text { Knowledge and } \\
\text { Food Intake } \\
\text { 2018/ Holanda } \\
\text { Games for Health } \\
\text { Journal: Research, } \\
\text { Development, and } \\
\text { Clinical } \\
\text { Applications }\end{array}$ & $\begin{array}{l}\text { Avaliar a eficácia a } \\
\text { curto prazo do jogo } \\
\text { Alien Health Game } \\
\text { projetado para } \\
\text { ensinar crianças da } \\
\text { Educação Básica } \\
\text { sobre nutrição e } \\
\text { escolhas } \\
\text { alimentares } \\
\text { saudáveis. }\end{array}$ & $\begin{array}{l}\text { Estudo Controle } \\
108 \text { crianças } \\
\text { ( } 10-13 \text { anos) } \\
\text { Alien Health } \\
\text { (experimental) } \\
\text { Controle ativo) } \\
\text { Super Shopper } \\
\text { (estático) } \\
\text { Videogame. }\end{array}$ & $\begin{array}{l}\text { O grupo Alien } \\
\text { Health teve melhor } \\
\text { conhecimento dos } \\
\text { macronutrientes no } \\
\text { pós-teste, } \\
\text { identificou com } \\
\text { mais clareza os } \\
\text { alimentos mais } \\
\text { saudáveis, mas não } \\
\text { houve diferença na } \\
\text { ingestão de } \\
\text { alimentos ricos em } \\
\text { nutrientes e/ou } \\
\text { densos em energia. }\end{array}$ & $\begin{array}{l}\text { A intervenção com o } \\
\text { Alien Health Game teve } \\
\text { o potencial de melhorar o } \\
\text { conhecimento nutricional } \\
\text { a curto prazo, mais } \\
\text { investigações são } \\
\text { necessárias antes que } \\
\text { este jogo seja aplicado } \\
\text { em futuros programas de } \\
\text { educação nutricional. }\end{array}$ \\
\hline $\begin{array}{l}\text { CHAGAS et al. } \\
\text { Rango Cards, a } \\
\text { digital game } \\
\text { designed to } \\
\text { promote a healthy } \\
\text { diet: a randomized } \\
\text { study protocol } \\
\text { 2020/ Brasil } \\
\text { BMC Public } \\
\text { Health. }\end{array}$ & $\begin{array}{l}\text { Avaliar o impacto } \\
\text { de intervenção } \\
\text { nutricional do jogo } \\
\text { Rango Carl sobre o } \\
\text { consumo alimentar, } \\
\text { conhecimento } \\
\text { nutricional e a } \\
\text { autoeficácia na } \\
\text { adoção de práticas } \\
\text { alimentares } \\
\text { saudáveis. }\end{array}$ & $\begin{array}{l}\text { Estudo } \\
\text { Randomizado } \\
319 \text { adolescentes } \\
\text { do ensino médio da } \\
\text { rede privada do } \\
\text { Distrito Federal } \\
\text { Jogo de cartas } \\
\text { digital Rango } \\
\text { Cards. }\end{array}$ & $\begin{array}{l}\text { O grupo de } \\
\text { intervenção } \\
\text { apresentou maior } \\
\text { conhecimento } \\
\text { sobre os efeitos do } \\
\text { consumo de frutas } \\
\text { e verduras e } \\
\text { melhora na redução } \\
\text { da ingestão de } \\
\text { sódio e preparo de } \\
\text { refeições } \\
\text { saudáveis. }\end{array}$ & \begin{tabular}{lr} 
O jogo digital Rango \\
Cards é potencialmente \\
capaz de \\
mudanças efetuar \\
autonomia & positivas, \\
autocuidado & \multicolumn{2}{c}{ do } \\
adolescentes quanto à \\
alimentação saudável.
\end{tabular} \\
\hline $\begin{array}{l}\text { ESPINOSA- } \\
\text { CURIEL et al. } \\
\text { Relationship } \\
\text { Between Children's } \\
\text { Enjoyment, User } \\
\text { Experience } \\
\text { Satisfaction, and } \\
\text { Learning in a } \\
\text { Serious Video } \\
\text { Game for Nutrition } \\
\text { Education: } \\
\text { Empirical Pilot } \\
\text { Study } \\
\text { 2020/México } \\
\text { JMIR Serious } \\
\text { Games }\end{array}$ & $\begin{array}{l}\text { Projetar e testar o } \\
\text { videogame sério } \\
\text { Food Rate Master } \\
\text { para ajudar as } \\
\text { crianças a melhorar } \\
\text { o conhecimento } \\
\text { sobre alimentos } \\
\text { saudáveis, } \\
\text { aumentar } \\
\text { ingestão a } \\
\text { alimentos } \\
\text { saudáveis e reduzir } \\
\text { a ingestão de } \\
\text { alimentos } \\
\text { ultraprocessados. }\end{array}$ & 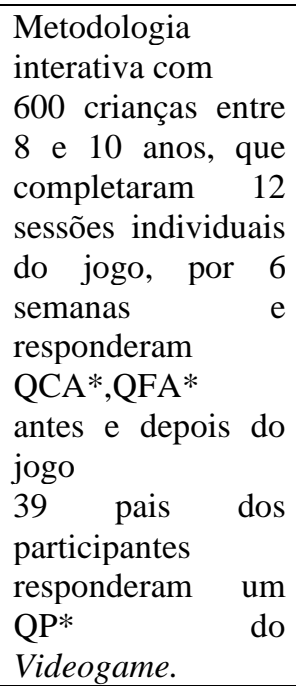 & $\begin{array}{lr}\text { As } & \text { crianças } \\
\text { aumentaram o nível } \\
\text { de conhecimento } \\
\text { nutricional } \\
\text { ingestão frequente } \\
\text { de alimentos } \\
\text { saudáveis } \\
\text { diminuíram } \\
\text { ingestão a } \\
\text { alimentos de } \\
\text { saudáveis e os pais } \\
\text { concordaram que o } \\
\text { jogo influenciou } \\
\text { positivamente o } \\
\text { comportamento } \\
\text { alimentar. }\end{array}$ & $\begin{array}{l}\text { O jogo de saúde Food } \\
\text { Rate Master mostrou ser } \\
\text { uma ferramenta viável } \\
\text { para ajudar as crianças a } \\
\text { aumentar seu } \\
\text { conhecimento alimentar } \\
\text { e melhorar } \\
\text { comportamento } \\
\text { alimentar. }\end{array}$ \\
\hline
\end{tabular}

*QCA, Questionário de Conhecimento Alimentar; *QFA,Questionário de Frequência Alimentar; *QP, Questionário de Percepção.

Fonte: As autoras. 


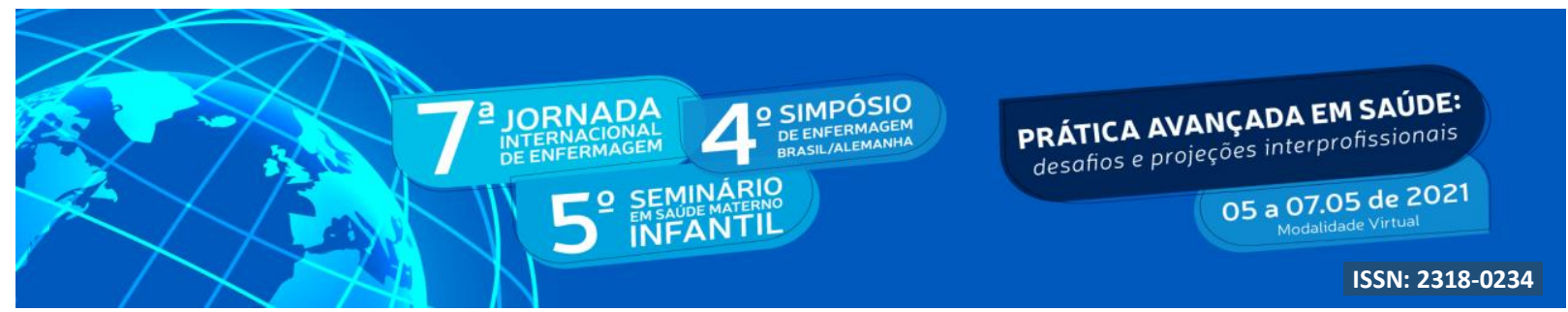

Percebeu-se que todas as pesquisas incluíram indivíduos de ambos os gêneros, com grande variação etária. Com relação ao tamanho amostral, somaram juntas 4.055 indivíduos. Já, no que se refere aos objetivos, todas tinham como enfoque a alimentação saudável. Dentre os jogos, três são jogos de cartas, um jogo de tabuleiro e dois videogames. Quanto à origem das publicações, um artigo brasileiro e cinco internacionais.

Em Corrêa; Fantin (2011), a aprendizagem por meio de videogame com estudantes revelou que menos de $10 \%$ disseram não aprender nada; cerca de 30\% fizeram referências a aprendizagens relacionadas a aspectos valorizados pelas escolas (raciocínio lógico, coordenação motora) ou ligados às disciplinas escolares, como aprender inglês e 62\% indicaram aprendizagens ligadas à "vida prática", porque não são necessariamente os saberes que os (as) alunos (as) reconhecem como valorizados pelas escolas e situam-se nas aprendizagens informais.

E, em Johnson (2005), os jogos eletrônicos atraem crianças e jovens sobretudo pela dimensão do desafio, da tomada de decisões e das regras que envolvem o seu contexto. E, um dos aprendizados principais dos jogos é a tomada de decisões, o que implica escolha e priorização: "Todos os benefícios intelectuais do jogo resultam dessa virtude fundamental, porque aprender como pensar, em última análise, tem a ver com aprender a tomar a decisão certa: pesar a evidência, analisar situações, consultar suas metas a longo prazo e, então, decidir".

\section{CONCLUSÃO}

Conclui-se, que os jogos voltados à EAN para serem utilizados, tanto no âmbito escolar, quanto em outros espaços, ainda, são escassos. Reforça-se, portanto, a necessidade de novos estudos na área, visto que os observados apresentaram resultados positivos em relação ao uso dessa ferramenta para promover a alimentação saudável. 


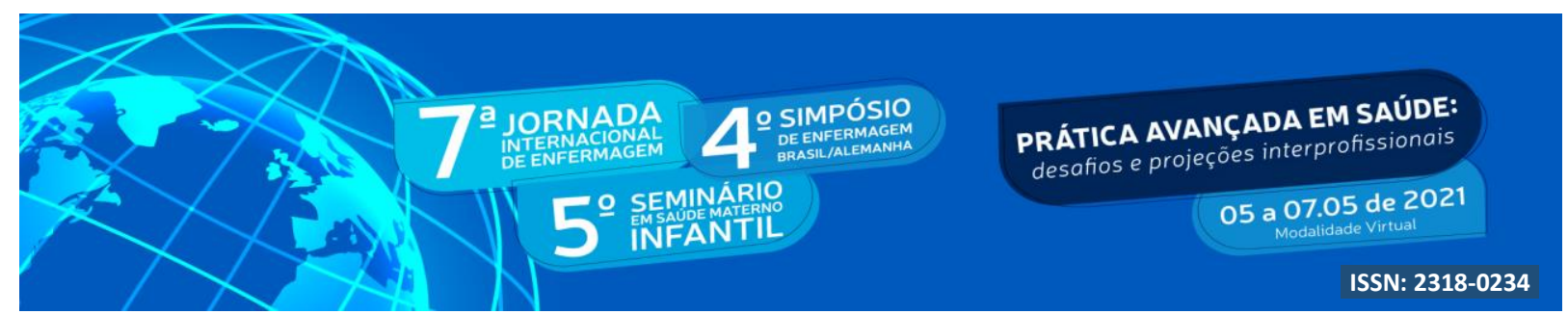

\section{REFERÊNCIAS}

BRASIL. Decreto ${ }^{\circ}$ 7.272, de 25 de agosto de 2010. Regulamenta a Lei no 11.346, de 15 de setembro de 2006, que cria o Sistema Nacional de Segurança Alimentar e Nutricional SISAN. Diário Oficial da União, Disponível em:

http://www.planalto.gov.br/ccivil_03/_ato2007-2010/2010/decreto/d7272.htm. Acesso em: 08 de março de 2021.

BRASIL. Ministério do Desenvolvimento Social e Combate à Fome. Marco de Referência de Educação Alimentar e Nutricional para as Políticas Públicas. Brasília: MDS; Secretaria Nacional de Segurança Alimentar e Nutricional, 2012. Disponível em:

http://www.mds.gov.br/webarquivos/publicacao/seguranca_alimentar/marco_EAN.pdf. Acesso em: 08 de março de 2021.

BRASIL. Ministério do Desenvolvimento Social- MDS Secretaria Nacional de Segurança Alimentar e Nutricional - SESAN. Brasília/DF, 2018. Princípios e Práticas para Educação Alimentar e Nutricional. Disponível em:

https://www.mds.gov.br/webarquivos/arquivo/seguranca_alimentar/caisan/Publicacao/Educac ao_Alimentar_Nutricional/21_Principios_Praticas_para_EAN.pdf. Acesso em: $08 \mathrm{de}$ março de 2021.

BRASIL. Ministério da Saúde. Secretaria de Atenção à Saúde. Departamento de Atenção Básica. Guia Alimentar para a População Brasileira / Ministério da Saúde, Secretaria de Atenção à Saúde, Departamento de Atenção Básica. - 2. ed., 1. reimpr. - Brasília: Ministério da Saúde, 2014. MS Brasília. Ministério da Saúde. Secretaria de Atenção à Saúde.

Departamento de Atenção Básica. 2014. Disponível em:

http://bvsms.saude.gov.br/bvs/publicacoes/guia_alimentar_populacao_brasileira_2ed.pdf.

Acesso em: 08 de março de 2021.

BRASIL. Ministério da Saúde. Secretaria de Atenção Primária à Saúde. Departamento de Promoção da Saúde. Guia alimentar para crianças brasileiras menores de 2 anos / Ministério da Saúde, Secretaria de Atenção Primária à Saúde, Departamento de Promoção da Saúde. Brasília: Ministério da Saúde, 2019. 265 p. : Il. ISBN 978-85-334-2737-2. Disponível em: http://189.28.128.100/dab/docs/portaldab/publicacoes/guia_da_crianca_2019.pdf. Acesso em: 08 de março de 2021.

CHAGAS, C. M. et al. Rango Cards, um jogo digital desenvolvido para promover uma alimentação saudável: um protocolo de estudo randomizado. BMC Public Health 18, 910 (2018). Disponível em: https://doi.org/10.1186/s12889-018-5848-0. Acesso em: 03 de março de 2021.

CORREA, E.; FANTIN, M. . Videogames: processos de aprendizagem cognitiva, social e cultural em jogo. In: 34a Reunião Anual da ANPED, 2011, Natal. Anais da 34a Reunião Anual da ANPED, 2011. p. 1-16 


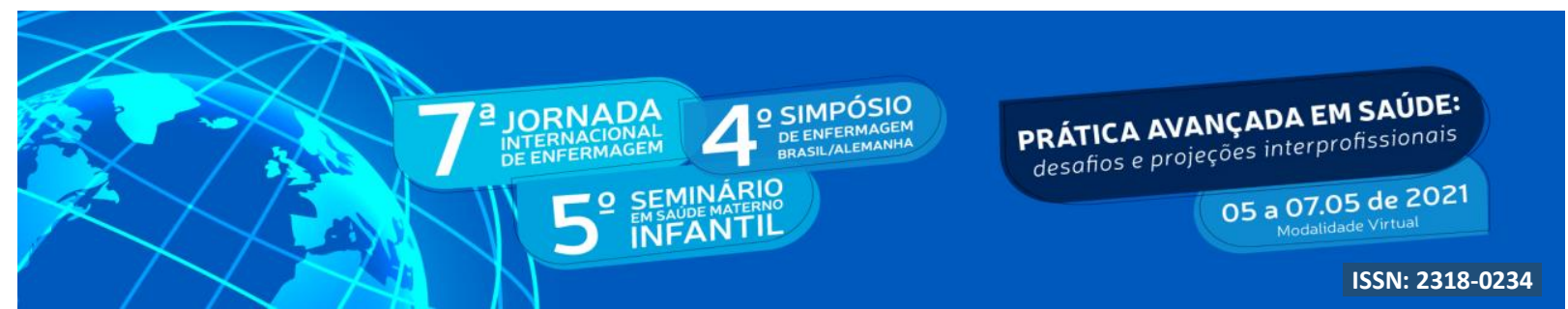

DAVANÇO, G. M.; TADDEI, J. A. A. C.; GAGLIANONE, C. P. Conhecimentos, atitudes e práticas de professores de ciclo básico, expostos e não expostos a Curso de Educação Nutricional. Revista Nutrição, Campinas, v. 17, n. 2, p. 177-184, abr./jun. 2004. Disponível em: http://www.scielo.br/scielo.php?script=sci_arttext\&pid=S1415-52732004000200004. Acesso em: 03 de março de 2021.

ESPINOSA-CURIEL et al.. Relationship Between Children's Enjoyment, User Experience Satisfaction, and Learning in a Serious Video Game for Nutrition Education: Empirical Pilot Study.JMIR Serious Games 2020;8(3):e21813. Disponível em:

https://games.jmir.org/2020/3/e21813 . Acesso em: 03 de março de 2021.

HERMANS, R. et al.. Feed the Alien! The Effects of a Nutrition Instruction Game on Children's Nutritional Knowledge and Food Intake. Games for Health Journal. Jun 2018. Volume 7, Number 3, 2018. Disponível em: http://doi.org/10.1089/g4h.2017.0055. Acesso em: 03 de março de 2021.

HUIZINGA, J. Homo ludens: o jogo como elemento da cultura. Trad. João Paulo Monteiro. 4.ed.. São Paulo: Perspectiva, 2000.

JONHSON, S. Surpreendente. A televisão e o videogame nos tornam mais inteligentes. Rio de Janeiro, Campus, 2005.

KISHIMOTO, T. M. (Org.). Jogo, brinquedo, brincadeira e a educação. 11. ed. São Paulo: Cortez, 2008.

KISHIMOTO, T. M. O jogo e a educação infantil. Perspectiva. Florianópolis, UFSC/CED, NUP, n. 22, p. 105-128. 2011 Disponível em: https://pt.scribd.com/doc/133175911/O-jogo-ea-educacao-infantil-Tizuko-Morchida-Kishimoto-pdf. Acesso em: 03 de março de 2021.

LAKSHMAN, R. R. et al. . A novel school-based intervention to improve nutrition knowledge in children: cluster randomised controlled trial.BMC Public Health; 10: 123, 2010 Mar 10. Disponível em:

https://bmcpublichealth.biomedcentral.com/articles/10.1186/1471- 2458-10-123\#Sec1. Acesso em: 03 de março de 2021.

PEREZ LOPEZ, I. J.; DELGADO FERNANDEZ, M.. Un juego de cartas durante los recreos escolares mejora los hábitos alimentarios en adolescentes. Nutr. Hosp., Madrid, v. 27, n. 6, p. 2055-2065, dic. 2012. Disponível em: http://dx.doi.org/10.3305/nh.2012.27.6.6071. Acesso em: 03 de março de 2021.

PIZIAK, V. . A pilot study of a pictorial bilingual nutrition education game to improve the consumption of healthful foods in a head start population. Int J Environ Res Public Health; 9(4): 1319-25, 201204.

Disponível em: https://www.mdpi.com/1660-4601/9/4/1319/htm. Acesso em: março de 2021. 


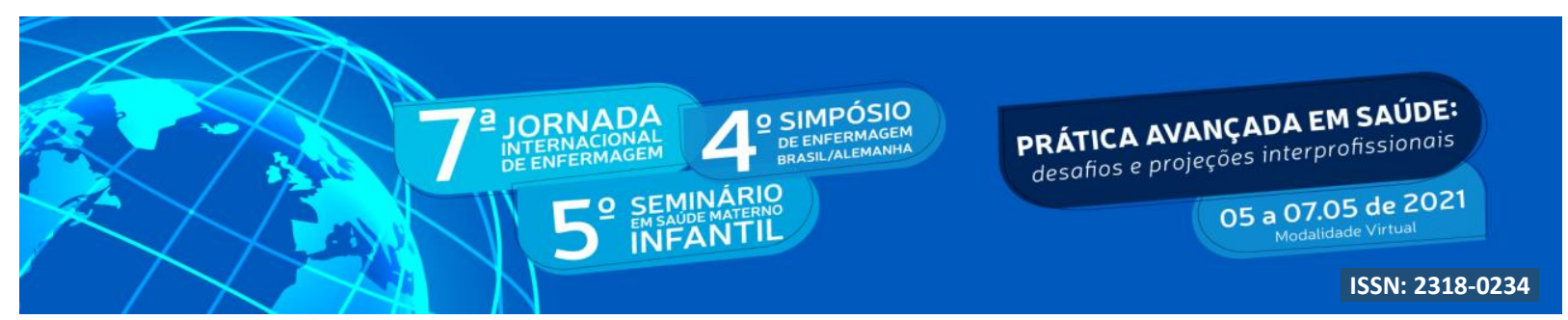

RAMOS, P.F. SANTOS, S.A.L. REIS, C.B.A. Educação alimentar e nutricional em escolares: uma revisão de literatura. Cad. Saúde Pública, Rio de Janeiro, 29(11):2147-2161, Nov.

2013. Disponível em: http://www.scielo.br/pdf/csp/v29n11/03.pdf. Acesso em: 03 de março de 2021. 